\title{
Cooperative or collaborative learning: Is there a difference in university students' perceptions?
}

\section{Aprendizaje cooperativo o colaborativo: ¿hay alguna diferencia en la percepción de los estudiantes universitarios?}

\author{
María Ángeles ANDREU-ANDRÉS \\ Universitat Politècnica de València
}

Recibido: Noviembre 2014

Evaluado: Febrero 2015

Aceptado: Marzo 2015

\begin{abstract}
The hypothesis that the same educational objective, raised as cooperative or collaborative learning in university teaching does not affect students' perceptions of the learning model, leads this study. It analyses the reflections of two students groups of engineering that shared the same educational goals implemented through two different methodological active learning strategies: Simulation as cooperative learning strategy and Problem-based Learning as a collaborative one. The different number of participants per group (eighty-five and sixty-five, respectively) as well as the use of two active learning strategies, either collaborative or cooperative, did not show differences in the results from a qualitative perspective.
\end{abstract}

Keywords: collaborative, cooperative, experiential learning, engineering education.

\section{Resumen}

La hipótesis de que un mismo objetivo educativo planteado como aprendizaje cooperativo o colaborativo en enseñanza universitaria no afecta a la percepción que los estudiantes tienen de dicho modelo de aprendizaje, guía este trabajo. En él se analizan las reflexiones de dos grupos de estudiantes de ingeniería que compartieron los mismos objetivos educativos implementados a través de dos estrategias metodológicas activas diferentes de aprendizaje: la simulación como estrategia de aprendizaje cooperativo y el aprendizaje basado en problemas como estrategia colaborativa. El número distinto de participantes por grupo (ochenta y cinco frente a sesenta $\mathrm{y}$ cinco, respectivamente) así como el uso de dos estrategias de aprendizaje activas, bien colaborativa o cooperativa, no arrojaron diferencias en los resultados del análisis cualitativo.

Palabras clave: colaborativo, cooperativo, aprendizaje a través de la experiencia, estudios de ingeniería.

Traditional engineering educational strategies and techniques have been criticized because they promote passive learning and a curriculum aimed at retention of facts that 
may not prepare learners for the innovative role of engineers (Prince, 2004; Felder and Brent, 2005; Michel, Cater and Varela, 2009; Smith, 2011; Felder and Hadgraft, 2013).

Currently engineering education is undergoing meaningful changes to meet the present demands of engineering practice (Meijers and den Brok, 2013, Watts et al., 2013). The Accreditation Board for Engineering and Technology (ABET, 2000) has specified eleven criteria to graduate students meanwhile in his study Passow (2012) states that, with few exceptions, out of these eleven criteria engineering graduates rate a cluster of competences composed of teamwork, communication, data analysis and problem-solving as the most important in their professional experience regardless their work environment. Collaboration and cooperation are two ABET accreditation required components of the engineering curriculum that in situations with asymmetry of knowledge among students have shown to be helpful to more competent peers as well as less-able mates (Stump, et al. 2011; Felder, 2012; Chan, 2012b).

These findings should have implications on the design of any engineering curriculum and the methodological strategies to be used. This is the case of an English course for engineers setting; in it team working, communication and problem solving skills are integrated into its contents through active and experiential learning strategies such as Simulation-based learning and Problem-based learning (PBL) - cooperative and collaborative learning, respectively - to enhance these competences and integrate the aforementioned components.

Despite the differences between collaborating and cooperating (Kessler, 1992; Panitz, 1999; Joung and Keller, 2004; Chung et al., 2011; Sulaiman, 2011; Watts et al., 2011; Aliah et al., 2012), there may be a considerable extent of disagreement among teachers' and learners' opinions as for their dissimilarities that, as Woods (1996) stated, it may not be the fault of the teaching method per se but the way it is introduced to the students. Therefore, analyzing the learners' feedback, their attitudes and feelings towards the methodological strategies used in class sessions - either collaborative or cooperative - are a priority. This allows lecturers to know what they think they learn when working cooperatively with a simulation and, collaboratively, with a problembased learning approach and test the hypothesis that structuring the same educational goal by following a cooperative or collaborative pattern does not affect the students' perceptions in higher education.

The following subsections of this introduction focus on the theoretical background of this research design, starting with the two active learning strategies used and concluding with collaborative and cooperative team working formation.

\section{Theoretical Background}

\section{Active and Experiential Learning: Simulation and Problem-based Learning}

The term active learning refers to any method, technique or strategy implemented in the lecture room with the aim of transforming the learning process into activities that foster the dynamic and reflective participation of students and accomplish their learning (Labrador and Andreu, 2008). It is a mode of instruction that focuses the 
responsibility of learning on the learners through carefully planned experiences (Montero-Fleta, 2013). Its use in education is not a new idea as it was most certainly the first method used.

If we admit that lecturing focuses on the teacher, active learning strategies underline the importance of the learners' activities in such a way that students are mentally active (Cameron, 1999; Cotner et al. 2013); their learning is most effective as they are involved in the learning experience rather than being passive recipients of the information (Pfeiffer, 1994; Freeman et al. 2014). In Simulation and PBL students interact, work out problems in proposals that are based on social constructivism, generating knowledge and meaning from their experiences; thus, as a social activity, group interdependency is a key element to gain and share learning and knowledge.

Related to active learning is experiential learning; that is, the learning acquired through reflection on doing, and at its heart is the challenge, situation or problem to be solved and from which we want students to acquire knowledge, skills and attitudes. Experiential learning theory (Kolb 1984; Kolb and Kolb, 2009; Chan, 2012a) provides a structure for communicating, interacting, leading, negotiating, solving conflicts and problems, among other skills, that form part of the professional competences to be gained from experience. These skills are becoming more prevalent in education as organizations increasingly rely on teams to get the work done (Kayes et al., 2005). Both Simulation and PBL are active learning strategies that involve learners in doing rather than in learning about something.

Simulation can offer authentic contexts that permit the integration of specific knowledge and the development of key components of professional competences. As a methodology it has multidisciplinary applications in fields such as business (Faria et al., 2009), engineering (Mayo, 2007), medicine (Bradley, 2006, Gaba, 2004), architecture (Agapiou, 2006), language learning (Gaudart, 1999; García-Carbonell and Watts, 2009; García-Carbonell et al., 2012; García-Carbonell et al. 2014) or when learning science at distance (Blake and Scanlon, 2007) among others.

The first programmed use of a simulation is attributed to the Prussian army in the nineteenth century as a consequence of their dissatisfaction with the unreliable results of their officer recruitment. Instead of asking candidates how they would act in a certain situation, the idea was to put them in that situation and observe what would happen; later this idea was embraced by the British and the American army (Jones, 1995).

Depending on the goals pursued, a simulation can either take a lesson or a whole semester but the phases of briefing and debriefing - before and after the action phase - must not be avoided. Research has shown that without appropriate feedback and debriefing (Leemkuil et. al., 2003) learners do not gain much from the experiential learning that simulations can facilitate (Min, 2004). The briefing stage is considered the phase of the information input: what the task consists of, the nature of the situation students are going to experience, the participants' roles and possible constraints as well as the contents (organized by the teacher) that students need to work on in order to participate in the simulation proper. 
The action stage is the main phase where students face their part of the real life scenario, take decisions, solve problems, interact, think critically, etc. with minimal or no interruption from the facilitator (the teacher). Once the action is completed, the third phase or debriefing occurs. The primary purpose for debriefing in an educational context is to facilitate participants an understanding of what has happened (Crookall, 2010); it permits them to reflect upon the experience, the decisions made, the results obtained as well as on what they did and what they should have done to learn from it.

PBL was introduced in the early 1970s at the Medical School of the McMaster University (Canada) although its intellectual history traces back to philosophers such as Socrates and Aristotle. Years later Maastricht University (The Netherlands) became the second university in the world to employ it for its medical program (Smith et al., 2005; Bouhuijs, 2011). Nowadays, it has spread in engineering (Savery, 2006; Machika and Abrahams, 2014), architecture (Kingsland, 1989; Bridges, 2007), nursing and business (Rideout and Carpio, 2001), teacher education (Hmelo-Silver, 2004), and language learning (Neville and Britt, 2007; Andreu-Andrés and García-Casas, 2010) among other disciplines.

In PBL students are confronted with problems that are ill-structured and do not have absolute answers in order to reflect the complexity of real-world situations. Working in teams, students identify what they already know, what they need to know, and how and where to access new information that may lead to the resolution of a problem. Students' learning results from the process of working towards the understanding or resolution of a problem or situation (Northwood et al., 2003; Lauridsen, 2012).

To start with, students produce a conditional analysis of the problem based on their prior knowledge. This fact makes them ask questions on issues initially explained or unknown that are used as learning objectives for them to study independently. After this self-study phase, participants inform their peers and share what they have learned (Moust et al. 2007). Learners are not expected to acquire a predetermined series of right answers but to engage with the ill-structured situation/problem presented. This way they generate hypotheses, identify the learning issues, gather the information they need to learn and the skills they need to gain to face it effectively; an independent study follows this process.

Group discussion of the acquired knowledge, as well as its application to solve the problem and the reflection on the process, round off the activity; this fact, most likely, will generate more problems and more learning needs (Rideout and Carpio, 2001; Jonassen, 2011). All this process can help them learn with complexity since there are no straightforward answers to problems or scenarios, as it happens in real life (Brundiers, 2010).

The main difference between Simulation and PBL lies in the fact that PBL offers a self-directed learning process in which learners decide what to study based on the problem case, question or scenario that drives their learning. Conversely Simulation structures the information that students receive to focus their learning on the intended curriculum. 


\section{Collaborative and cooperative team working formation}

Research has demonstrated that learning becomes more effective when students work in teams (either collaborative or cooperative), express their opinions and thoughts and work together towards the solution of a problem (Johnson and Johnson, 1989; Smith, Duncan and Cook, 2013). At the same time this approach enables them to develop self-reflection and critical thinking skills (Brindley et al., 2009).

Team-working in engineering courses is considered an outstanding preparation for the learners' future professional life (Smith et al., 2011) in spite of the different pitfalls that may be found ${ }^{1}$ because - among other reasons - students seldom receive specific training before team-working assignments are given (Lingard, 2010) or when certain reluctance appears on the part of those who are not used to it. It is a technique that becomes successful and effective when there are positive inter-dependency and individual responsibilities among team members (Yesilyurt, 2010; Law, 2011).

Collaborative and cooperative concepts are occasionally considered synonymous and when students actively participate in a problem or situation certain transitions between both systems can be appreciated. Oxford (1997) states that cooperative learning is more structured and directive to students about how to work in teams than collaborative learning; it involves students working together to reach a common goal under conditions such as positive interdependence, individual accountability, face-toface interaction, appropriate use of cooperative skills and group processing (Johnson et al., 1991; Dooly, 2008). On the contrary, it is underlined that collaborative learning is less structured with open-ended and complex tasks that have no one specific answer and where the instructor is not the class authority but a facilitator for the group action (Jacob, 1997; Laal and Laal, 2012).

Bruffee (1995) argues that cooperative learning dominates in primary and secondary school since the teacher places in a position of power as s/he structures the process. In collaborative learning it is the learner who assumes this responsibility even though it is the teacher who also provides an environment in which students seek and create knowledge themselves; the role of the teacher is less the traditional expert in the classroom and it is perhaps more appropriate for university students since it requires an in-depth preparation, experience in team-working and intellectual development. Nevertheless, in both systems learners discover knowledge and transform it through interaction with their peers. For full discussion on both systems and the massive confusion that reigns in the literature of higher education over terminology see Barkley et al. (2005), Panitz (1999) and Coppola (1996), among other authors.

In our opinion it is the lecturer who has to decide which system (cooperative or collaborative) and what level of authority and control are advisable to accomplish the goals. In this research, the Simulation was designed to follow a more cooperative learning approach whereas the PBL was more in line with collaborative learning, although they could have been designed otherwise. Both methodological strategies

\footnotetext{
${ }^{1}$ Studies such as the one done by Oakley et al. (2004) guide on the effective design and management of teams.
} 
took place in a university environment and pursued the same educational goals in an English course.

The following sections focus on the aims and scope of this study as well as the materials and method followed that lead the reader to the analysis of results and conclusions.

\section{Aim and Scope of the Study}

Both cohorts were formed by students of English of the same engineering degree over the course of an academic year. Besides developing fluency, accuracy, and correctness in written and spoken language, the course pursued the acquisition of professional competences composed of teamwork, communication, data analysis and problem-solving, as stated by Passow (2012). To this end, either the Simulation or the PBL designs aimed to make participants face a job hunting experience.

The educational experience for one of the groups, chosen at random, was devised as a simulation. The lecturer structured the contents and process to be followed; that is, during the briefing and the debriefing phase. In the action phase or simulation proper, the lecturer did not participate but observed the process to facilitate students to learn from the experience.

Likewise, for the second group, the educational experience was designed as a PBL where participants had to collaborate with their peers in a less structured activity. They had to identify what they already knew about the topic and to discover what they needed to learn; what would permit them to face and succeed in the job hunting as well as to know how and where to find the information needed. The lecturer became the facilitator for the group action.

To test the hypothesis that structuring the same educational goal following a cooperative or collaborative pattern does not affect the students' perceptions, the research pursued to answer the following questions:

- What happened in the process of working collaboratively to conclude tasks involving the Simulation Job Hunting, according to the participants?

- Did a different team working methodological strategy provoke differences in the students' perceptions regarding the process followed (Simulation Job Hunting versus PBL Job Hunting, cooperative versus collaborative)?

- Did the results obtained in a bigger population, working with the Simulation, appear in a smaller one with participants from different background and nationalities as it was the case of the students working with PBL?

\section{Materials and Method}

One of the groups consisted of eighty-five engineering students divided into teams of four members in the last year of their degree; they were heterogeneous in their 
communication competence in English but homogeneous in their nationalities, all of them Spanish speakers although they had to use English as vehicle of communication.

For three weeks these students focused their in-class and out-of-class activity on working cooperatively during the three phases of the Simulation Job Hunting, designed to reach the same educational goals as the PBL. They were not able to select their team-mates and the average age of the group was 23 . The qualitative analysis was based on the study of their reflections on the experience with Simulation. They were written in English and prepared individually, forming a corpus of 14,290 words.

The second group consisted of a smaller number of participants (sixty-five students), divided into teams of five members, heterogeneous not only in their communication competence in English but also in their backgrounds and nationalities: Dutch, French, Polish, Czech, Turkish and German (on an Erasmus exchange) together with Spaniards and Argentineans. All of them were about to finish their studies in our university and were also studying English as a foreign language. To reach similar educational goals these participants worked collaboratively for the same amount of time on the multi-task Job Hunting, structured as a PBL. The average age of this smaller cohort was also 23. The qualitative analysis was based on the study of their reflections on the experience with PBL. They were written in English and prepared individually, with a corpus of 10,079 words.

The experiences took place at the end of the course after having been using team working and active learning strategies in their in-class activities. Our analysis is based on the study of the reflections on the processes experienced with the simulation and the PBL taken from their individual English portfolios, as one of the possible ways a qualitative research can collect data (Wester and Peters, 2001; Flick, 2002).

The analysis was initiated with a preliminary and open codification of data followed by the development of initial categories that were limited and integrated into conceptual categories. The analysis of their reflections required a codification of all the data, line by line and, at times word by word, as underlined by Strauss (1987) until data saturation was reached (Mikel, 2003).

\section{Results}

Four large categories related to (1) learning and discoveries, (2) teamwork, (3) difficulties encountered and (4) applicability of what was learned were generated; the following subsections develop them. For the sake of anonymity the segments reported here that support these categories are identified by the letter $\mathrm{P}$ and a number or the letter S and a number (when quoting testimonies of participants involved in the PBL or the Simulation, respectively).

\section{Learning and Discoveries}

As shown in figure 1, participants affirmed they learned the process to be followed when applying for a job as expressed by two of the testimonies collected hereunder, 
'The simulation helped us to understand job ads and apply for one of the posts by writing our $C V$ and an application letter in the adequate register, highlighting our knowledge and skills for the post' (S3).

'Thanks to the PBL I have become more familiar not only with the strategy that we had already used in another subject, but with the process we need to follow when looking for a job' (P18).

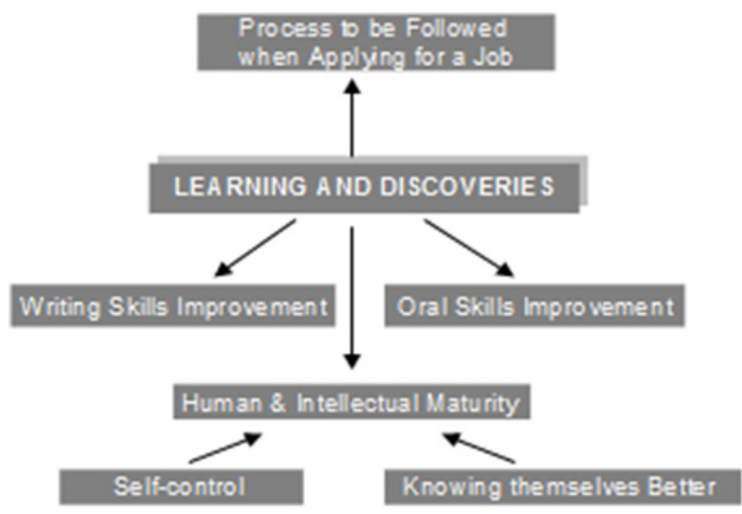

Figure 1. Learning and Discoveries in Simulation and PBL

Besides improving their writing skills, the experience provided them with good opportunities to enhance their oral skills in a foreign language. For example,

'In the first phase of the simulation I was shocked; the fact of having to speak in front of the panel and the rest of my classmates during the action phase made me feel nervous as I thought I would not be able to cope with it even in my mother tongue' (S22).

'The surprise was that after preparing for the job interview and observing how other interviewees acted, I started to feel more comfortable at the time I realized I was improving my communication skills and broadening the specific vocabulary' (P50).

Working in teams as they might have to do as professionals brought with it new learning about themselves. They also believed that the multi-task helped them to ' $b e$ less obstinate' (P48) and 'more patient' (S60). Some participants focused on other relevant issues concerning their careers, such as the importance of 'working with a deadline' ( $\mathrm{P} 19)$ as well as 'the importance of explaining their viewpoints' (S21), which obliged them 'to think twice before acting and speaking, to choose the right words to 
avoid any misunderstanding' as well as 'to listen to others more carefully in order to come to agreements' (S78); something that can be seen as part of their human and intellectual maturity, especially in those teams working with PBL, heterogeneous in their backgrounds and nationalities.

It is worth mentioning the similarities in both macro-groups' perceptions despite the different strategy used; not only did both groups coincide with what they considered they learned and discovered but emphasized the importance of self-control and knowing themselves to better work in teams.

\section{Teamwork}

Even though team-working is highly valued by organizations, participants recognized that it is a competence rarely practiced during their studies (figure 2 displays the results obtained in this category). The following testimonies echo this idea:

'In my opinion the most important thing we learned during this experience is how to work and behave as a team' (P21).

'Team working is tough, but the simulation has given us opportunities to enhance this skill, something that many teachers mention in class but very few put into practice' (S68).

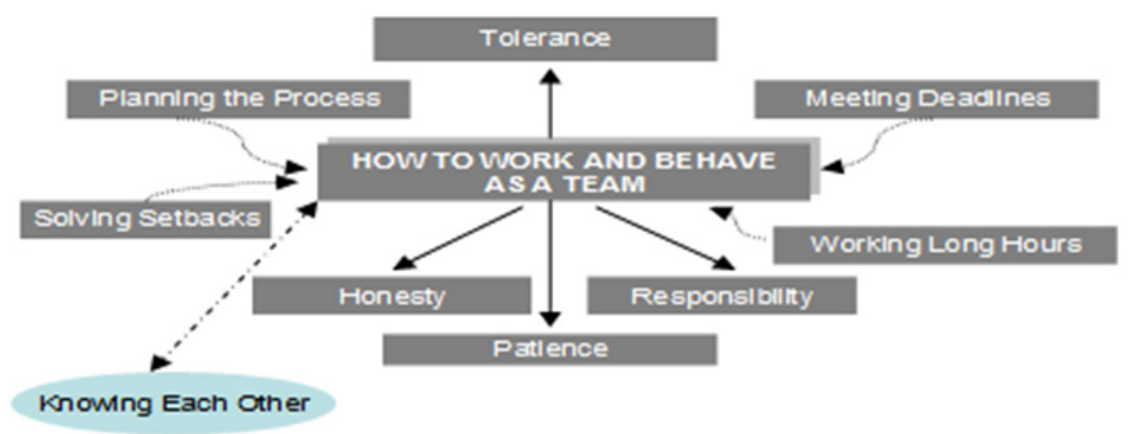

Figure 2. Teamwork

For these students, teamwork meant 'planning the process' (P39), 'working in and out of class' (P29), 'collaborating' (S67) with their team-mates and 'making an effort to meet deadlines' (S81); in other words, 'collaborating, planning the process, meeting deadlines and solving setbacks' (P15). 
Perhaps the most striking finding regarding team-working was what the experience revealed the students about themselves and their relationships with others. For example,

'I consider that, in order to work well together as my team has done, everyone has to be sincere, patient, responsible, more tolerant and listen to each other' (S46). Something that might appear basic to someone trained in teamwork, but totally new to those who experience it almost for the first time.

Most of the students expressed their satisfaction with their groups. 'At the beginning we did not know each other much, though most of us met in other group-work activities of the subject; the experience helped us to know each other and become friends' (P39).

The fact that students were not able to freely select their teams did not seem to worry them since there was no reference to it in their reflections. Participants did not comment anything on the optimum number of members per team in the Simulation (four in this experience), what implies that they identified it as adequate. This number was adopted after having paid attention to the comments made from the multicultural group working with PBL who considered that five members were a disadvantage to work collaboratively.

\section{Difficulties Encountered}

Throughout the three phases of the simulation difficulties mainly referred to the fact of 'working in teams' (S2) and 'communicating in a foreign language as a must' (S11), even though these participants did not belong to different cultures and nationalities. In those working with PBL the pitfalls referred not only to the task itself but to the fact of working with team-mates from different countries (cultures) and, therefore, ways of facing work responsibilities within a limited time frame; nevertheless, for the simulation cohort deadlines 'helped them to organise' (S50). For both groups, the need of communication skills in a foreign language also made the whole task more difficult at the time it improved their learning (see figure 3).

The beginning of both projects was generally difficult and slow, even though most students considered that they were 'problem-free' in the end (S10 and P28). Participants agreed that 'almost everyone worked' (S17 and P31) in their team, making up for others' absences and tardiness. In spite of that, one of the groups in the PBL recognized that they did not reach their goal due to '[their] lack of responsibility and interest' (P41). 'No student decided to plan and organize the activity' (P42) and they openly recognized that '[their] attitude made them waste their time and the opportunity of learning' (P43). 


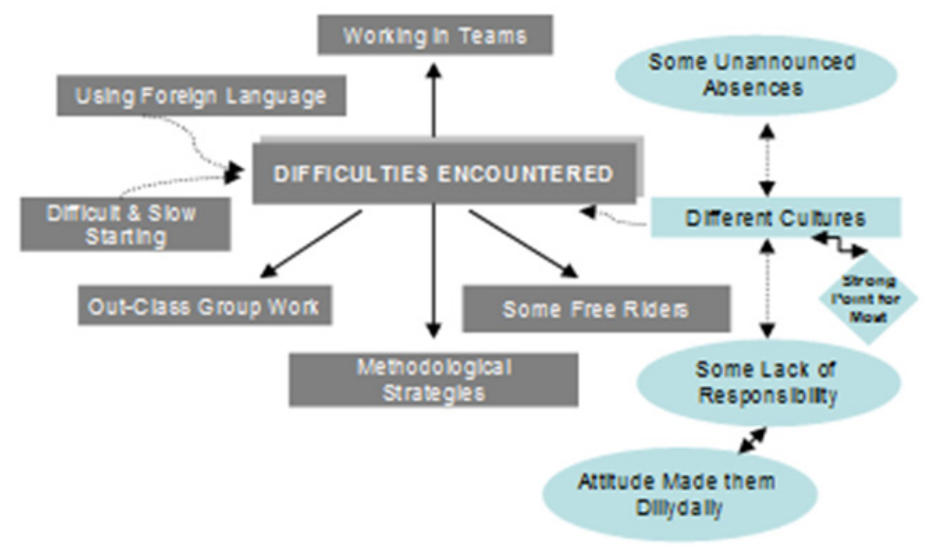

Figure 3. Difficulties encountered

One delicate aspect which only some students commented was the subject of freeriders who worked very little or whose contribution was minimal when saying that 'most of [his/her] team-mates took initiative and worked with constructive criticism but one didn't do anything, just what s/he felt like and none of us complained' (P57).

Another group 'had problems with the unannounced absences of one member (...) even though [they] achieved a lot and felt satisfied with the results' (S17). A problem that lectures could have detected and rectified within the time frame of the PBL and Simulation by using rubrics that had stimulated and assessed the students' participation throughout the process.

Information and communication technologies facilitated their task and helped them to overcome certain obstacles in out-class group work and meetings through e-mail and Google-docs.

A drawback for most of them was the methodological strategy itself, especially at the beginning: 'In spite of having worked in teams during most of the subject activities, understanding how the simulation worked and what [their] goal as a team was it took [them] time and several group discussions' (S8); however, as the activity progressed some teams forgot they were students 'and behaved as professionals seeking for a job and dealing with ordinary pitfalls when working with peers' (P10). Participants were, in general terms, too much accustomed to have everything organized by teachers and after the experience most of them become aware of how those strategies were preparing them to face their professional future.

A majority of participants in the PBL considered that different backgrounds and nationalities were 'a strong point of the experience since [they] learned that different 
cultures - and not only language competence - can become an obstacle for teamworking unless interest in understanding the others is put into practice' (P32).

Despite the fact that for some participants belonging to different cultures was hand in hand with a higher or lower degree of responsibility and, in some cases it 'was the responsible of [their] failure as a group' (P3), in the experience with an homogeneous origin of participants it was proved that this feeling was generally more related to the case of working in teams per se than to the heterogeneous origin of their members. Students' perceptions towards teamwork may be influenced not only by their personality (Myers et al. 2009) or communication skills (De Rosa and Lepsinger, 2010) but also by their experience on team-working (Falls et al. 2014); a skill that it is not lectured but learned by doing.

\section{Applicability of What Was Learned}

Many students underlined that the experience taught them how to apply for a job, as in the following examples,

'The experience is going to help me face a job hunting situation with better probabilities of success' (P46). 'I feel able to use what we learned when applying for a job or seeking personnel for our own company' (S63). A feeling also shared by the multicultural group working with PBL to whom the experience made them 'become more tolerant with each other' (P32); however, they linked this feeling with the circumstance of working with people from different countries, rather than with teamworking proper.

\section{Conclusions}

Although some of the aforementioned outcomes might be also achieved by means of more traditional lectures and home assignments, implementing Simulation and PBL in an engineering programme met most of ABET objectives. On the whole they are the ability to function on multidisciplinary and multicultural teams, to work as an effective team member, to be able to communicate, to be adaptive, resourceful and responsive to changes. The experiences lived through Simulation and PBL also facilitated the development of essential skills that employers demand such as: Identifying the information needed, combining facts and knowledge from different areas, finding out how to solve problems or situations and being able to self-assess (Northwood et al., 2003).

Regarding the first research question (What happened in the process) it can be affirmed that students from both groups considered they lived an experience quite similar to the one they would probably have to face at the end of their university studies. A feeling that is grounded on four large categories that help understand the processes undergone: Their learning and discoveries, what teamwork consisted of according to the experience lived - the difficulties they encountered and overcome, as well as the applicability of what they learned, no matter groups cooperate or 
collaborate to reach their goal. Instead of referring to the weak points of the experiences, students mentioned the difficulties they had to cope with that turned into learning.

As regards the second research question (Did a different team working methodological strategy provoke differences in the students' perceptions regarding the process followed?) it can be asserted that there is no difference among the results obtained in both active learning strategies. Surprisingly, participants in both experiences even focused on the same four large categories.

As can be seen, the results obtained in this study (third research question: Did results obtained in this study appear in smaller populations with different background and nationalities, as in the PBL?) are also collected in a smaller cohort with different backgrounds and nationalities where participants considered that belonging to different cultures was directly related to a higher or lower degree of the team-members' responsibility. The experience with a bigger and homogeneous group showed that such a difference was more related to team-working per se, striving for reaching their goals and sharing responsibilities, than to a heterogeneous origin of the participants; the feeling that almost all members of the group actively worked — but not all — also appeared in the second group.

Through the learners' reflections it can be stated that the perceptions from the two different cohorts of students were almost identical despite the different number of participants (eighty-five and sixty-five), the two teaching-learning strategies used with common basic principles, and the different nationalities and cultures. The beginning of both projects was slow and difficult, no matter it was a structured (cooperative) or a self-directed learning process (collaborative); this was a consequence of different variables that played, in our opinion, an important role in both strategies such as the challenge of team-working, communicating in a foreign language and coping with peers' personalities and attitudes.

As common denominator both populations experimented team-working activities in our subject previous to the Simulation and PBL proper; they pursued the same goals and shared the same average age and university studies what allow us to confirm the hypothesis that structuring the same educational goal following a cooperative or collaborative pattern does not affect the students' perceptions from a qualitative perspective.

In conclusion, we can say that, despite the limitations of this research, these findings call for attention. Firstly, when university students actively participate in a team-working experience, designed either as a cooperative or collaborative learning strategy, their perceptions are almost identical, in spite of the literature that can be read on their dissimilarities (Henri and Rigault, 1996; Dooly, 2008; Watts, et al., 2011; Laal and Laal, 2012). In our view it is the lecturer who has to decide what level of authority and control are adequate to achieve the educational goals by making students cooperate or collaborate. Both approaches involve them in doing rather than in learning about something and demand from professors an exhaustive planning and certain amount of expertise in team-working strategies. 
Secondly, the differences in the number of participants per group and the use of two active learning strategies, either collaborative or cooperative, did not show differences in the results. It is important to highlight that according to the participants, four seemed to be the optimum number of team members to work collaboratively; in contrast, they pondered five as the adequate number of students to work cooperatively.

The results show how experiential learning (Simulation and PBL, in this case) can be combined with the contents of any subject to help students enhance relevant criteria specified by ABET for Engineering and Technology; in particular, those competences rated as the most important in their professional experience by engineering graduates regardless their work environment: Teamwork, communication, data analysis and problem solving.

The active observation of the lecturer was not enough to detect any team dysfunction as the ones mentioned by some participants; this reflection invites us to improve future designs by using assessment rubrics throughout the process that can help detect and rectify them. A quantitative analysis of the results of future experiences will ratify or refute the hypothesis tested in this research.

\section{References}

ACCREDITATION BOARD FOR ENGINEERING AND TECHNOLOGY, Inc. (2000). Criteria for accrediting engineering programs. Baltimore, MD: Anthor.

AGAPIOU, A. (2006). The Use and Evaluation of a Simulation Game to teach Professional Practice Skills to Undergraduate Architecture Students. Journal for Education in the Built Environment, 1(1), 3-14.

ALIAH, F.; MOHD-YUSOF, KH.; HELMI, S. \& HASSIM, M. (2012). Engineering Students' Perceptions on Learning through Cooperative Problem-based Learning for the First Time. American Society for Engineering Education (ASEE) Annual Conference, 1-17. Retrieved from http://www.asee.org/public/conferences/8/papers/2957/view [10 October 2013].

ANDREU-ANDRÉS, M.A. \& GARCÍA-CASAS, M. (2010). Problem-based learning applied to LSP. Ibérica, 19, 33-54. Retrieved from http://www.aelfe.org/documents/02_19_Andreu.pdf 22 [June 2011].

BARKLEY, E.F.; CROSS, K.P. \& MAJOR C. H. (2005). Collaborative Learning Techniques: A Handbook for College Faculty. San Francisco, CA., Jossey-Bass.

BLAKE, C. \& SCANLON, E. (2007). Reconsidering simulations in science education at a distance: features of effective use. Journal of Computer Assisted Learning, 23, 491-502.

BOUHUIJS, P. (2011). Implementing Problem-based Learning. Why is it so hard? REDU, 9(1), 17-24. Retrieved http://redaberta.usc.es/redu/index.php/REDU/article/view/190/164 $\quad\left[\begin{array}{ll}10 & \text { January }\end{array}\right.$ 2012]. 
BRADLEY, P. (2006). The history of simulation in medical education and possible future directions. Medical Education, 40, 254-262.

BRIDGES, A. (2007). Problem-based Learning in Architectural Education. Proceedings of CIB $24^{\text {th }}$ W78 Conference Maribor 2007. CIB (International Council for Building). Retrieved from http://itc.scix.net/data/works/att/w78-2007-116-049Bridges-b.pdf [1 July 2011].

BRINDLEY, J.E.; WALTI, C. \& BLASCHKE, L.M. (2009). Creating effective collaborative learning groups in an online environment. The International Review of Research in Open and Distance Learning, 10(3), 1-9. Retrieved from http://www.irrodl.org/index.php/irrodl/article/view/675/1271 [15 March 2012].

BRUFFEE, K.A. (1995). Sharing our toys: Cooperative learning versus collaborative learning. Change, 27, 12-18.

BRUNDIERS, K.; WIEK, A. \& REDMAN, C. L. (2010). Real-world learning opportunities in sustainability: from classroom into the real world. International Journal of Sustainability in Higher Education, 11(4), 308-324.

CAMERON, B.J. (1999). Active Learning: Green Guide 2. Halifax, Nova Scotia, Society for Teaching and Learning in Higher Education.

COPPOLA, B. P. (1996). Progress in Practice: Exploring the Cooperative and Collaborative Dimensions of Group Learning. The Chemical Educator, 1(1). Retrieved from http://chemeducator.org/sbibs/s0001001/spapers/11 cop897.htm [12 July 2008].

COTNER, S.; LOPER, J.; WALKER, D. \& BROOKS CH. (2013). It's not you, it's the room. Are the High-Tech, active learning classrooms worth it? Research and Teaching 42(6), 82-88.

CROOKALL, D. (2010). Serious Games, Debriefing, and Simulation/Gaming as a Discipline. Simulation and Gaming, 41(6), 898-920.

CHANG, C. (2012a). Exploring an experiential learning project through Kolb's Learning Theory using a qualitative research method. European Journal of Engineering Education, 34(4), 405-415.

CHAN, C. (2012b). Identifying and understanding the graduate attributes learning outcomes in a case study of community service experiential learning project. International Journal of Continuing Engineering Education and Life-Long Learning, 22 (1-2), 148-159.

CHUNG, E.; HITCHCOCK, M.; OH, S.; HAN, E. \& WOO, Y. (2011). The relationship between student perception of tutor performance and tutors' background in problem-based learning in South Korea. International Journal of Medical Education, 2, 7-11.

DEROSA, D. \& LEPSINGER, R. (2010). Virtual team success: A practical guide for working and leading from a distance. San Francisco, CA: Jossey-Bass. 
DOOLY, M. (2008). Constructing Knowledge Together. In M. Dooly (Ed.). Telecollaborative Language Learning. A guidebook to moderating intercultural collaboration online (pp. 21-34). Bern: Peter Lang.

FALLS, I.; BAHHOUTH, V.; CHUANG, CH. \& BAHHOUTH, J. (2014). Factor influencing Students' Perceptions of Online Teamwork. Sage OPEN, JanuaryMarch 2014, 1-9. Retrieved from http://sgo.sagepub.com/content/4/1/2158244014525415 [2 January 2014].

FARIA, A.J.; HUTCHINSON, D.; WELLINGTON, E.J. \& GOLD, S. (2009). Developments in Business Gaming: A Review of the Past 40 Years. Simulation \& Gaming, 40, 464-487.

FELDER, R.M. (2012). Engineering Education: A Tale of Two Paradigms. In McCabe, B., Pantazidou, M., and Phillips, D., (Eds.). Shaking the Foundations of Geo-Engineering Education ( 9-14). Leiden: CRC Press.

FELDER, R.M. \& BRENT, R. (2005). Understanding student differences. Journal of Engineering Education, 94 (1), 57-72.

FELDER, R.M. \& HADGRAFT, R. (2013). Educational practice and educational research in engineering: partners, antagonists, or ships passing in the night? Journal of Engineering Education, 102 (3), 339-345.

FLICK, U. (2002). Qualitative Research - State of the Art. Social Sciences Information, 41 (1), 5-24.

FREEMAN, S.; EDDY, S.; MCDONOUGH, M.; SMITH, M.; OKOROAFOR, N.; JORDT, H. AND WENDEROTH, M. (2014). Active learning increases student performance in science, engineering and mathematics. PNAS, 111 (23), 8410-8415.

GABA, D. (2004). The Future of Simulation in Healthcare. Qual. Saf. Health Care, 13, 2-10.

García-CARBONELL, A. \& WATTS, F. (2009). Simulation and Gaming Methodology in Language Acquisition. In Guillén-Nieto (Ed.) Intercultural Business Communication and Simulation and Gaming Methodology (pp. 285-316). Oxford: Peter Lang.

GaRCÍA-CARBONELL, A.; WATTS, F. \& ANDREU-ANDRÉS, M.A. (2012). Simulación telemática como experiencia de aprendizaje de la lengua inglesa. REDU, 10(3), 301-323. $\quad$ Retrieved from http://www.redu.net $/$ redu/index.php?journal $=$ REDU\&page $=$ article\&op $=$ view \&path $\% 5 B \% 5 \mathrm{D}=340$ [21 January 2014].

GARCÍA-CARBONELL, A.; ANDREU-ANDRÉS, M.A. \& WATTS, F. (2014). Simulation and Gaming as the Future's Language of Language Learning and Acquisition of Professional Competences. In Duke and Kriz (Eds.) Back to the Future of Gaming (214-227). Germany: WB Verlag,.

GAUDART, H. (1999). Games as teaching Tools for Teaching English to Speakers of other Languages. Simulation and Gaming, 30 (3), 282-291. 
HMELO-SILVER, C. E. (2004). Problem-based learning: What and how do students learn? Educational Psychology Review, 16 (3), 235-266.

JACOB, T. (1997). Collaborative learning. Small group learning page, College One Level Team, National Institute of Science Education, University of Wisconsin. Retrieved from http://www.wcer.wisc.edu/ARCHIVE/CL1/CL/que stion/TQ13.htm [8 September 2010].

JOHNSON, D.W. \& JOHNSON, R.T. (1989). Cooperation and competition: Theory and research. Edina, $\mathrm{MN}$ : Interaction Book Company.

JOHNSON, D.W.; JOHNSON, R.T. \& SMITH, K.A. (1991). Cooperative Learning: Increasing College Faculty Instructional Productivity. ASHE-ERIC Higher Education Report No. 4, George Washington University.

JONASSEN, D. (2011). Supporting Problem Solving in PBL. Interdisciplinary Journal of Problem-based Learning, 5(2), 95-112. Retrieved from http://dx.doi.org/10.7771/1541-5015.1256 [3 July 2013].

JONES, K. (1995). Simulations. A handbook for teachers and trainers. London: Kogan Page.

JOUNG, S. \& KELLER, J. (2004). The effects of high-structure cooperative versus low-structure collaborative design of decision change, critical thinking and interaction pattern during online debates. On the practice of educational communications and technology. Chicago: ERIC, 316-320.

KAYES, A.B.; KAYES, D. Ch. \& Kolb, D.A. (2005). Experiential learning in teams. Simulation and Gaming, 36, 330-354.

KESSLER, C. (1992). Cooperative language learning: a teacher's resource book. Englewood Cliffs, NJ: Prentice Hall Regents.

KINGSLAND, A. J. (1989). The assessment process in architecture at Newcastle (pp. 121-130). In Wallis (Ed.) Problem-based learning: The Newcastle workshop. Newcastle: Faculty of Medicine, University of Newcastle.

KOLB, D.A. (1984). Experiential Learning: Experience as the Source of Learning and Development. Englewood Cliffs NJ: Prentice Hall.

KOLB, A. \& KOLB, D. (2009). The Learning Way: Meta-cognitive Aspects of Experiential Learning. Simulation \& Gaming, 40 (3), 297-327

LAAL, M., \& LAAL, M. (2012). Collaborative learning: what is it? Procedia-Social and Behavioral Sciences, 31, 491-495.

LABRADOR-PIQUER, M.J. \& ANDREU-ANDRÉS, M.A. (2008). Metodologías Activas. Valencia: Editorial UPV.

LAURIDSEN, B. (2012). Problem-based Learning applied to Team Environments: A Visual Literature Review. TCC Proceeding. Retrieved from http://etec.hawaii.edu/proceedings/2012/lauridsen.pdf [18 March 2013]. 
LAW, Y. (2011). The effects of cooperative learning on enhancing Hong Kong fifth graders' achievement goals, autonomous motivation and reading proficiency. Journal of Research in Reading, 34(4), 402-425.

LEEMKUIL, H.; DE JONG, T.; DE HOOG, R. \& CHRISTOPH, N. (2003). KM QUEST: A collaborative Internet-based simulation game. Simulation \& Gaming, 31 (1), 89-111.

LINGARD, R. W. (2010). Teaching and assessing teamwork skills in engineering and computer science. Journal of Systemics, Cybernetics and Informatics, 18 (1), 34-37.

MACHIKA, P. \& ABRAHAMS, Ch. (2014). Problem-based learning in Construction Engineering within a South African Context. International Journal of Learning, Teaching and Educational Research, 3 (1), 69-82.

MASTERS, J. (1955). The History of Action Research. In Hughes (Ed.) Action Research Electronic Reader. The University of Sydney. Retrieved from http://www.behs.cchs.usyd.edu.au/arow/Reader/rmasters.htm [2 January 2009].

MAYO, M.J. (2007). Games for Science and Engineering Education. Communications of the ACM, 50(7), 30-35.

MEIJERS, A. \& DEN BROK, P. (2013). Engineers for the Future. An essay on education at TU/e in 2030. Eindhoven: University of Technology. Retrieved from http://www.tue.nl/uploads/media/TUE_Vision_of_Education_2013.pdf [5 June 2014].

MICHEL, N.; CATER, J. \& VARELA, O. (2009). Active versus passive teaching styles: an empirical study of student learning outcomes. Small Business Institute, vol. 33 (1), 55-67.

MIKEL, G. (2003). ESL Teachers' Views on Visual Language. A Grounded Theory. The Reading Matrix, 3 (3), 137-168.

MIN, R. (2004). Designing dynamical learning environments for simulation: Microworlds applets on the World Wide Web (pp. 57-69). In Niegemann, Leutner \& Bruncken (Eds.) 6th Proceedings of EARLI, SIG . Munchen: Waxman. Retrieved from http://projects.edte.utwente.nl/pi/papers/AbstractErfurt.htm [1 April 2011].

MONTERO-FLETA, B. (2013). Enhancing Innovation Competences through a research-based simulation: From Framework to Hands-on Experience. PortaLinguarum, 20, 239-252.

MOUST, J.; BOUHUIJS, P.A.J. \& SCHMIDT, H.G. (2007). El aprendizaje basado en problemas: guía del estudiante. Cuenca: Ediciones de la Universidad de Castilla-La Mancha.

MYERS, S.; BOGDAN, L.; EIDSNESS, M.; JOHNSON, A.; SCHOO, M.; SMITH, N., \& ZACKERY, B. (2009). Taking a trait approach to understanding college students' perception of group work. College Student Journal, 43, 22-831. 
NEVILLE, D. \& BRITT, D. (2007). A Problem-based Learning Approach into Integrating Foreign Languages to Engineering. Foreign Language Annals, 40(2), 226-246.

NORTHWOOD, M.D.; NORTHWOOD, D.O. \& NORTHWOOD, M.G. (2003). Problem-based Learning (PBL): From the Health Sciences to Engineering to ValueAdded in the Workplace. Global Journal of Engineering Education, 7(2), 157-164.

OAKLEY, B.; FELDER, R.M.; BRENT, R. \& ELHAJJ, I. (2004). Turning Student Groups into Effective Teams. Journal of Student Centered Learning, 2(1), 9-34.

OXFORD, R. (1997). Cooperative Learning, Collaborative Learning, and Interaction: Three Communicative Strands in the Language Classroom. Modern Language Journal, 81, 443-56.

PANITZ, Th. (1999). Collaborative versus cooperative learning: A comparison of the two concepts which will help us understand the underlying nature of interactive learning. Retrieved from http://files.eric.ed.gov/fulltext/ED448443.pdf 28 [October 2014].

PASSOW, H.J. (2012). Which ABET Competencies do Engineering Graduates Fid most Important in their Work? Journal of Engineering Education, 101(1), 95-118.

PFEIFFER, J.W. (1994). Theories and Models in Applied Behavioral Science, 2. San Diego, California: Pfeiffer \& Company.

PRINCE, M. (2004). Does Active Learning Work? A review of the Research. Journal of Engineering Education, 93(3), 223-231.

RIDEOUT, E. \& CARPIO, B. (2001). The Problem Based Learning Model of Nursing Education. In Rideout (Ed.) Transforming Nursing Education through PBL (pp. 2150). Boston: Jones and Bartlett Publishers.

SAVERY, J.R. (2006). Overview of Problem-based Learning: Definitions and Distinctions. Interdisciplinary Journal of Problem-based Learning, 1(1), 9-20.

SMITH, G.G.; SORENSEN, C.; GUMP, A.; HEINDEL, A.J.; CARIS, M. \& MARTINEZ, C.D. (2011). Overcoming student resistance to group work: Online versus face-to-face. The Internet and Higher Education, 14(2), 121-128.

SMITH, K.A. (2011). Cooperative Learning: Lessons and Insights from Thirty Years of Championing a Research-Based Innovative Practice. 41st ASEE/IEEE Frontiers in Education Conference, 1-7. Retrieved from http://personal.cege.umn.edu/ smith/docs/Smith-FIE-CL-1240-10-draft.pdf $\quad[12$ September 2013].

SMITH, K.A.; SHEPPARD, SH. D.; JOHNSON, D.W. \& JOHNSON, R. (2005). Pedagogies of Engagement: Classroom-Based Practices. Journal of Engineering Education, 94(1), 87-101.

SMITH, M.; DUNCAN, M. \& COOK, K. (2013). Graduate Employability: Student Perceptions of PBL and its Effectiveness in Facilitating their Employability Skills. 
Practice and Evidence of Scholarship of Teaching and Learning in Higher Education, 8(3), 217-240.

STRAUSS, A.L. (1987). Qualitative Analysis for Social Scientists. New York: Cambridge University Press.

STUMP, G.S.; HILPERT, J.C.; HUSMAN, J.; CHUNG, W.T. \& KIM, W. (2011). Collaborative Learning in Engineering Students: Gender and Achievement. Journal of Engineering Education, 100(3), 475-497.

SULAIMAN, F. (2011). Students' Perceptions on the Suitability of Implementing an Online Problem-based Learning in Physics Course. Malaysian Journal of Educational Technology, 11(1), 5-13.

THIAGARAJAN, S. (1992). Using games for debriefing. Simulation and Gaming. An International Journal, 23(2), 161-173.

WATTS, F.; GARCÍA-CARBONELL, A. \& RISING, B. (2011). Student Perceptions of Collaborative Work in Telematic Simulation. Journal of Simulation/Gaming for Learning and Development, 1(1), 1-12.

WATTS, F.; GARCÍA-CARBONELL, A.; ANDREU-ANDRÉS, M.A.; STANGE, CH. AND HELKER, H. (2013). Assessment of Innovation Competence. In Lehto, A. \& Penttilä (Eds.) Pedagogical Views on Innovation Competence and Entrepreneurship (pp. 44-56). Turku: University of Applied Sciences. Retrieved from http://julkaisumyynti.turkuamk.fi/filemanager/productfiled/1227file1Upload.pdf\#pa ge $=45$ [13 January 2014].

WESTER, F. \& Peters, V. (2001). An Introduction to the Principles and Practice of our Method of Qualitative Analysis. In P. Pieterse (Ed.) Desmond Tutu's Message. A Qualitative Analysis (pp. 112-136). Boston: Brill.

WOODS, D.R. (1996). Problem-based Learning for Large Classes in Chemical Engineering. In Wilkerson \& Gijiselaers (Ed.) Bringing Problem-based Learning to Higher Education: Theory and Practice (pp. 91-100). San Francisco: Jossey-Bass Publishers.

YESILYURT, E. (2009). The views of students on the effect of cooperative learning on student behaviours. Firat University Journal of Social Science, 19(2), 161-178.

\section{Correspondencia con la autora}

María Ángeles ANDREU-ANDRÉS

Universitat Politècnica de València

ETS Arquitectura - Lingüística Aplicada

Camino de Vera, $\mathrm{s} / \mathrm{n}$

46022 Valencia

e-mail: maandreu@idm.upv.es 